\title{
Iron-rich hot springs in Japan, a microbiogeochemical guided tour
}

FATIMA LI-HAU ${ }^{1,2^{*}}$, MAYUKO NAKAGAWA $^{1,2}$, LEWIS M. WARD $^{1,3}$, YUICHIRO UENO ${ }^{1,2}$, SHAWN MCGLYNN ${ }^{1,2}$

${ }^{1}$ Dept. of Earth and Planetary Sciences, Tokyo Institute of Technology, Meguro, Tokyo 152-8551, Japan

(*correspondence:. fatimali@elsi.jp)

${ }^{2}$ Earth-Life Sciences Institute, Tokyo Institute of Technology, Meguro, Tokyo 152-8550, Japan

${ }^{3}$ Harvard University, Cambridge, MA, United States

About 27,200 geothermal systems have been reported in Japan.[1] Each hot spring harbors a distinctive set of components (geological, chemical and biological), but their similarities/differences and its effect on biological diversity are yet to be completely elucidated.

Iron-rich hot springs could represent a window to the ferrous, reducing and anoxic oceans in Proterozoic era. They can also provide clues on microbial community structure, potential biosignatures, adaptations to this conditions, and biological succession to more present-day conditions. During 2019, Tsubakiyama onsen (Tsb, Aomori prefecture), Kowakubi onsen (Kk, Akita prefecture), Okuoku-hachikurou onsen (OHK, Akita prefecture), Furutobe onsen (Ftb, Aomori prefecture) and Jinata onsen ( $\mathrm{J}$, Tokyo prefecture) were surveyed in order to understand the dynamics of diverse ironrich environments. We present the preliminary results of the geochemistry and microbiology present in these iron-rich hot spings. In all hot springs, $\mathrm{Fe}^{2+}$ concentration ranged from $\sim 60$ to $200 \mu \mathrm{M}$. [2] Carbonate (and organic carbon) isotopes provide information on carbon flow. Amplicon and metagenome sequencing provide the first insights of which microbes inhabit the springs

[1] Ministry of the Environment, Japan. The State of Use of Hot Springs in Japan in the Fiscal Year 2017. Available online: https://www.env.go.jp/nature/onsen/pdf/2-4_p_1.pdf (accessed on Feb 21.2020). In Japanese.

[2] Ward, Lewis M. and Idei, Airi and Nakagawa, Mayuko and Ueno, Yuichiro and Fischer, Woodward W. and McGlynn, Shawn E. (2019) Geochemical and metagenomic characterization of Jinata Onsen, a Proterozoic-analog hot spring, reveals novel microbial diversity including irontolerant phototrophs and thermophilic lithotrophs. Microbes and Environments, 34 (3). pp. 278-292. ISSN 1342-6311. PMCID PMC6759342. 